\title{
Musas insubmissas: \\ Estudo de "Inês" (1974), um filme de coletivo sobre uma presa política brasileira
}

Unsubmissive muses:

Study of the human rights film "Inês" (1974) about a Brazilian political prisioner

Les Insoumuses:

Recherche à propos du film collectif «Inês » (1974) et une prisonnière politique

\section{Patricia Furtado Mendes Machado}

Doutora em Comunicação e Cultura ECO-UFRJ. Professora de cinema da PUC-RJ.

\section{Thais Continentino Blank}

Professora Adjunta da Escola de Ciências Sociais da FGV CPDOC e do Programa de Pós-graduação em História, Política e Bens Culturais FGV CPDOC. Autora do livro Cinema Doméstico Brasileiro (2020, Appris). Email: thais.blank@fgv.br

\section{RESUMO}

Neste artigo, analisamos o curta Inês (1974), video militante realizado sobre a prisão e tortura sofrida pela presa política Inês Etienne Romeu. 0 video encontra-se arquivado no Centre Audiovisuel Simone de Beauvoir, em Paris, idealizado por Norma Bengell e Delphine Seyrig foi realizado por um coletivo de mulheres feministas. Em nossa análise propomos resgatar o processo de fabricação da obra percorrendo as pistas deixadas pela rede de mulheres que permitiram a realização e a circulação do curta.

PALAVRAS-CHAVE: cinema militante; ditadura militar; movimento feminista

Dossiê Crise, Feminismo e Comunicação - https://revistaecopos.eco.ufrj.br/

ISSN $2175-8689$ - v. 23, n. 3, 2020

DOI: 10.29146/eco-pos.v23i3.27608 


\section{ABSTRACT}

In this paper, we analyze the short film Inês (1974), about the arrest and torture suffered by political prisoner Inês Etienne Romeu. The video is archived at the Centre Audiovisuel Simone de Beauvoir, in Paris. Conceived by Norma Bengell and Delphine Seyrig, it was made by a collective of feminist women. In our analysis, we investigate the production process of the film by following the tracks left by the network of women that made it possible.

KEYWORDS: militant cinema; military dictatorship; feminist movement

\section{RESUMÉ}

Dans cet article, nous analysons le court métrage Inês (1974), une vidéo militante sur l'arrestation et la torture subies par la prisonnière politique Inês Etienne Romeu. La vidéo est archivée au Centre Audiovisuel Simone de Beauvoir, à Paris. Conçu par Norma Bengell et Delphine Seyrig, le court métrage a été réalisé par un collectif de femmes féministes. Dans notre analyse, nous proposons d'examiner le processus de production de l'œuvre à partir des traces laissées par le réseau de femmes qui ont permis sa réalisation et diffusion.

MOT-CLÉ: cinéma militant ; dictature militaire ; mouvement féministe

No acervo do Centre Audiovisuel Simone de Beauvoir, em Paris, encontra-se um filme realizado em 1974 sobre a tortura e a violência sofridas por uma presa política brasileira no período da ditadura militar. Inês (1974, 19min), dirigido pela atriz e cineasta Delphine Seyrig, pode ser considerado um filme raro: nunca foi exibido no Brasil e permanece desconhecido entre cineastas e pesquisadores brasileiros. Criado em 1982, o Centre Audiovisuel Simone de Beauvoir se define como uma instituição feminista que possui como objetivos principais a conservação e criação de documentos audiovisuais que dizem respeito à história das mulheres, seus direitos, suas lutas e suas criações artísticas. A coleção do Centro é constituída por mais de 1300 títulos de vídeos e filmes ${ }^{1}$, dentre eles o curta Inês.

Neste artigo, propomos nos debruçar sobre o filme Inês alinhando a análise estética à busca de informações sobre o contexto de produção e circulação das imagens. A partir do filme, desejamos explorar os diferentes papéis desempenhados pelo cinema militante feminista do período. Em um primeiro tempo, como agente na

\footnotetext{
${ }^{1}$ https://www.centre-simone-de-beauvoir.com/ Acesso em 26 de agosto de 2020

Dossiê Crise, Feminismo e Comunicação - https://revistaecopos.eco.ufrj.br/

ISSN $2175-8689$ - v. 23, n. 3, 2020

DOI: 10.29146/eco-pos.v23i3.27608
} 
formação de uma rede internacional de luta feminista, em um segundo tempo, como documento e testemunho do caráter misógino do sistema de repressão da ditadura militar no Brasil.

0 relatório final da Comissão Nacional da Verdade, divulgado em 2014, identificou 1843 vítimas de tortura durante a ditadura, mas admite que esse número pode ter sido bem maior. 0 capítulo 10 do volume 1 é dedicado às denúncias da prática da violência sexual contra as mulheres sequestradas e torturadas nos órgãos de repressão política. Como ressalta Maria Amélia de Almeida Telles, vítima de tortura que participou da elaboração do relatório, o sistema repressivo "utilizou-se da discriminação de gênero para reforçar os estereótipos femininos de submissão e dependência emocional, afetiva e política. 0 tempo todo, a repressão política procurou coisificar e explorar a condição de mulheres" (2015, p.1001).

Os testemunhos de sobreviventes da tortura mostram a forma muito própria como a violência era praticada contra elas: as ameaças e execução de abuso sexual e estupro foram táticas intimidadoras constantes ${ }^{2}$. 0 ódio específico dos torturadores direcionado às mulheres era, entre outros motivos, consequência de um olhar reacionário para o mundo, como já mostraram Anette Goldberg (1987), Danielle Tega (2010) e Letícia Marotta (2019). As pesquisadoras relatam, a partir de diferentes perspectivas, como a participação das mulheres nas organizações de esquerda implicaram um rompimento radical com os valores e expectativas de uma sociedade conservadora e como essa ruptura se refletia nos métodos de tortura dos agentes da repressão.

Inês Etienne Romeu, a personagem do filme francês que tratamos aqui, foi vítima dessa violência em uma prisão clandestina ${ }^{3}$. Integrante de uma organização

\footnotetext{
2 Além dos diversos testemunhos presentes no relatório que dão detalhes sobre essa violência, podemos trazer também os testemunhos no cinema. Como o de Maria Auxiladora Barcellos que conta para a câmera dos cineastas Luiz Sanz, Saul Landau e Haskell Wexler que foi ameaçada de ter os seios cortados com a tesoura e que foi obrigada a encostar o corpo e simular relações sexuais com o companheiro de militância durante a tortura.

${ }^{3}$ No depoimento que consta no processo judicial, Inês conta detalhes das torturas. "Fui várias vezes espancada e levava choques elétricos na cabeça, nas mãos e nos seios" ... "fui violentamente castigada..uma semana de choques elétricos, banhos gelados na madrugada, telefones, palmatórias. Espancaram-me no rosto até ficar desfigurada. A qualquer hora do dia ou da noite sofria agressões físicas e morais. "Márcio" invadia minha cela para examinar meu ânus e verificar se "Camarão" havia
} 
que se tornou alvo da repressão política da ditadura militar, a Vanguarda Popular Revolucionária (VPR), Inês foi presa em 1971, aos 29 anos, em São Paulo, por participação no sequestro do embaixador suíço no Rio de Janeiro, ocorrido em dezembro de 1970. Barbaramente violentada já nas primeiras horas de prisão, ela foi entregue ao Centro de Informações do Exército (CIE), que mantinha clandestinamente uma casa em Petrópolis, usada para interrogatórios sob tortura e execução de prisioneiros políticos ${ }^{4}$. Na chamada Casa da Morte, Inês ficou encarcerada por 96 dias. Tornou-se a única sobrevivente que passou por ali e escreveu um imenso relatório denunciando as torturas e estupros que sofreu, os crimes que presenciou, os nomes de vítimas e algozes e as tentativas de assassinato a que foi submetida 5 .

O material que preserva a memória desses momentos terríveis vividos por Inês estava restrito aos documentos da polícia política, aos arquivos judiciais, ao acervo pessoal de Inês Etienne doado recentemente ao Arquivo Público de São Paulo, além de entrevistas posteriores em que ela relata o que viveu no passado. Apesar de não existirem imagens do que aconteceu no cativeiro, dois pequenos filmes singulares são importantes registros materiais que podem contribuir para a elaboração dessa memória, especialmente a partir de uma perspectiva feminista.

Além do filme francês, um filme doméstico guarda as marcas de outro tipo de violência policial cometida contra Inês. Trata-se do registro do casamento dela com Jarbas Silva Marques, que cumpria parte dos sete anos de prisão a que tinha sido condenado por conta da sua militância política. Na época, a situação de Inês era mais

praticado sodomia comigo". Este Márcio obrigou-me a segurar em seu pênis enquanto se contorcia obscenamente. Durante esse período fui estuprada duas vezes por Camarão e era obrigada a limpar a cozinha completamente nua, ouvindo gracejos e obscenidades, os mais grosseiros”. E ainda: "Dr. Roberto, um dos mais brutais torturadores, arrastou-me pelo chão, segurando-me pelos cabelos, depois tentou estrangular-me e só me largou quando perdi os sentidos. Esbofetearam-me e deramme pancadas na cabeça. Colocavam-me completamente nua, de madrugada, no cimento molhado, quando a temperatura estava baixíssima"

${ }^{4}$ A Casa da Morte foi criada para atender a uma nova estratégia de intensificação do combate às organizações armadas de esquerda pela ditadura. Nessa nova etapas, o aparelho repressivo passou a contar com bases secretas e equipes especializadas na execução de uma política de extermínio e desaparecimento forçado das principais lideranças das organizações em luta aberta contra o regime ditatorial.

5 Todas essas informações estão contidas no Relatório da Comissão Nacional da Verdade em um capítulo dedicado à Casa da Morte.

Dossiê Crise, Feminismo e Comunicação - https://revistaecopos.eco.ufrj.br/

ISSN $2175-8689$ - v. 23, n. 3, 2020

DOI: 10.29146/eco-pos.v23i3.27608 
dramática do que a do noivo: em 1971, ela foi condenada à prisão perpétua. Eles não se viam desde 1963, quando se conheceram em Belo Horizonte. Em 1975, o casal deixou a prisão rapidamente e trocou alianças em uma rápida cerimônia no Palácio da Justiça, no Centro do Rio, acompanhados pela polícia. Foi um casamento político, que servia para proteger a integridade física de Inês ${ }^{6}$.

A cerimônia foi filmada por Bruno Scharfstein, com uma câmera Super-8, a pedido da irmã da noiva. A intenção não era produzir um souvenir de um momento feliz, mas uma prova de vida da militante. 0 casamento foi registrado porque a família da noiva tinha consciência de que ela corria risco de morte dentro da prisão e temia um atentado durante essa breve saída. As imagens serviriam então como testemunho do que de ruim viesse a acontecer. No relatório escrito por Inês quando deixou a Casa da Morte, em outubro daquele ano, ela declara que temia ser objeto de queima de arquivo:

Pelos fatos porque passei durante o meu cativeiro, onde fui torturada e vi companheiros sofrendo e morrendo, pelas conversas que mantenho com agentes secretos que me visitam, tenho motivos para acreditar que os meus carcereiros pretendem me eliminar falseando a maneira e as razões da minha morte" (Inês Etienne, 1971, relatório incluído entre os documentos da Comissão de Direitos Humanos da OAB em 19797).

Inês corria riscos porque foi uma testemunha chave no esclarecimento dos crimes cometidos pelo Estado brasileiro na Casa da Morte durante a ditadura militar. As imagens que registram o casamento permaneceram esquecidas,

\footnotetext{
${ }^{6}$ Em 1975, a Assembleia Geral da ONU coroou o Ano Internacional das Mulheres, na esteira do movimento feminista internacional. Ao mesmo tempo, os militares diziam que não havia presos políticos no Brasil. Inês, no entanto, havia sido condenada à prisão perpétua.

${ }^{7} 0$ relatório foi escrito por Inês Etienne em 18 de setembro de 1971 quando internada na Casa de Saúde Santa Maria, em Belo Horizonte, em consequência da violência que sofreu no cativeiro. 0 documento foi entregue à Comissão de Direitos Humanos na OAB, em 1979, junto a outros documentos que denunciavam o que Inês tinha presenciado na Casa da Morte. Disponível em http://www.epsjv.fiocruz.br/upload/doc/DEPOIMENTO_INES.pdf. Acesso julho de 2020.
} 
guardadas com o cinegrafista amador ${ }^{8}$ por décadas em um fundo de armário ${ }^{9}$. 0 filme, que tem pouco mais de quatro minutos de duração, é um vestígio do tempo em que Inês Etienne esteve encarcerada. Certos traços contidos nas imagens revelam a tensão do casamento, como a câmera escondida da polícia, que se abaixa, treme ou perde o foco quando sente algum tipo de ameaça. Também podemos perceber que o cinegrafista opta por não se deter nos rostos dos convidados, para não identificá-los, assim como assume o risco de se aproximar para enquadrar o camburão onde estavam os noivos e o jipe com soldados do exército do lado de fora do prédio.

É curioso perceber que, por conta do clima de ameaça constante, até a entrada magistral da noiva, que estamos tão acostumados a ver nas cenas de casamento dos filmes domésticos, dá lugar a um plano escuro, tremido e desfocado. É no momento da cerimônia, que dura apenas um minuto, que o cinegrafista, enfim, se aproxima do casal e mostra os detalhes das roupas que vestiam, das expressões e dos olhares trocados naqueles instantes. Bruno usa o recurso do zoom para registrar os rostos, as mãos que assinam o livro, o beijo que sela o compromisso. No extracampo estão os policiais militares e do Departamento de Ordem Política e Social, o DOPS.

\footnotetext{
${ }^{8}$ Em entrevista para essa pesquisa, Bruno contou que era então estudante de economia e tinha uma Super-8 em casa que costumava usar de forma recreativa para filmar belas paisagens e atividades nos momentos de lazer. Esse foi o primeiro e único uso político que o cinegrafista deu ao equipamento. As imagens produzidas revelam o seu desconforto na filmagem. Bruno não estava inserido em nenhum círculo de cinema militante, essa era a sua primeira experiência de gravação em um ambiente de tensão

${ }^{9}$ Chegamos a esse material através de uma reportagem publicada no site do jornal $O$ Globo, quando entramos em contato com o realizador. Bruno conta que nem entregou o material para a família depois e que o filme ficou guardado com ele durante 40 anos, até ser publicado por conta da reportagem. In: https://oglobo.globo.com/brasil/casamento-como-ato-politico-na-ditadura17684694. Acesso em julho de 2020.
}

Dossiê Crise, Feminismo e Comunicação - https://revistaecopos.eco.ufrj.br/

ISSN 2175-8689 - v. 23, n. 3, 2020

DOI: 10.29146/eco-pos.v23i3.27608 


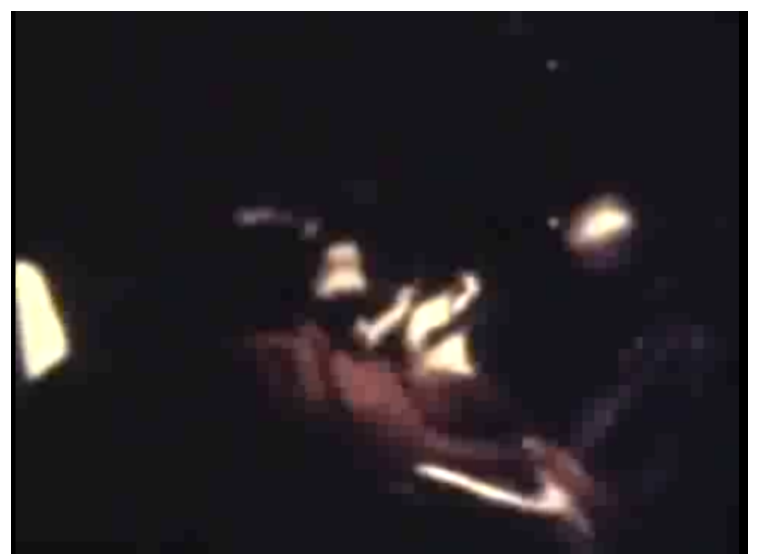

FIG. 1 - Fotograma casamento de Inês Etienne em filme doméstico.

O que não foi enquadrado pela câmera de filmar é, no entanto, registrado na fotografia retirada por outro amigo da família presente ao evento: a presença ostensiva de homens fardados ao lado de Inês e Jarbas. Uma segunda fotografia mostra a dramaticidade da cena: Jarbas chega ao prédio da Justiça algemado com as mãos para frente acompanhado de Inês. A presença das algemas e dos policiais retira das imagens de um evento familiar o caráter de domesticidade e revelam que aquele não era um casamento como os outros. Depois que a câmera foi desligada, como lembra Bruno, os noivos foram algemados e levados de volta à prisão.

Se as imagens domésticas que guardam traços da violência sofrida por Inês em pequenos detalhes - como o camburão, as algemas e a vigilância policial -, existem por conta de uma estratégia privada e familiar de defesa da vida da militante, o filme produzido na França por mulheres que não a conheciam é resultado de uma mobilização pela luta por sua liberdade. Inês foi realizado para ser exibido no Primeiro Congresso Internacional de Mulheres de Frankfurt, que reuniu cerca de 600 mulheres vindas de 13 países nos dias 16 e 17 de novembro de 1974 . O objetivo do congresso era coordenar lutas precisas para o ano de 1975, que foi decretado pela ONU como Ano Internacional da Mulher. No Congresso, mulheres que assistiram o filme começaram uma campanha internacional que exigia a liberação imediata de Inês.

Interessa-nos neste artigo investigar os mecanismos e as redes construídas entre mulheres que tornaram o filme possível, entender como se cruzam a história 
da militante presa no Brasil e das feministas que usavam o cinema como arma de combate na França, analisar de que modo o filme aborda a vida e a experiência da tortura de Inês Etienne e quais os traços da misoginia do sistema repressivo estão presentes ali. Para tanto, trabalharemos com a noção de "arquivos cruzados", proposta pela historiadora das imagens Sylvie Lindeperg (2013).

No livro Nuit et Brouillard: un film dans l'histoire (2007), Lindeperg realiza um mergulho no processo de produção do filme Noite e Neblina (1956), de Alain Resnais. Nesse mergulho, a historiadora produz uma análise dos embates que cercaram a fabricação da obra trazendo à tona uma rede de intrigas, dificuldades, avanços e conquistas que marcaram a produção e exibição do filme, mas que não são visíveis nas imagens. A recuperação dessa história é feita a partir do cruzamento de diferentes documentos produzidos na órbita das imagens: inúmeras versões do roteiro, documentos de censura, cartas trocadas entre os membros da equipe, diferentes versões de montagens, críticas na imprensa, etc. Sua proposta é desvendar o contexto de produção do filme a partir dos documentos usados como fonte de informação e os modos como essa história até então invisível é narrada e montada.

Na pesquisa que desenvolvemos em torno de filmes amadores produzidos no contexto da ditadura militar ${ }^{10}$ e que, por sua vez, nos levou ao filme militante Inês, temos como objetivo não só aplicar o método de Lindeperg, como refletir e reformular suas propostas para o contexto brasileiro e para a realidade material e simbólica dos filmes com os quais trabalhamos. Nesse sentido, é importante destacar, que o trabalho de Lindeperg se interessa por imagens que fazem parte de um sistema de grande circulação e visibilidade, como é o caso dos registros da Segunda Guerra Mundial e do filme Noite e neblina, já a pesquisa que realizamos recupera objetos que estão à margem da história do cinema e das práticas de patrimonialização e preservação.

\footnotetext{
10 Em 2017, iniciamos a pesquisa (....escondemos o nome da pesquisa por conta da invisibilidade de autoria para o parecer...) que propõe mapear, coletar e disponibilizar imagens em movimento realizadas no âmbito privado entre 1964 e 1985. Foi através dessa pesquisa, que conta com apoio do CNPq com o financiamento de uma bolsa PIBIC, que chegamos ao filme Inês, de Delphine Seyrig.
} 
Um coletivo feminista de vídeos militantes.

Ao longo dos anos 1960/1970, o movimento feminista na França ganha força concomitantemente ao surgimento no país dos coletivos de cinema militante que tinham como objetivo a produção de filmes de combate, contrainformação, intervenção e mobilização social ${ }^{11}$. Nessa época foram formados os primeiros coletivos de mulheres que retomam e reinventam práticas engajadas ao produzir filmes sobre a luta feminista. Nesses filmes, as mulheres tratam de questões como o direito ao aborto e a luta pela autonomia sexual e social feminina, assim como encontram a oportunidade de ocupar funções como a da direção, o que lhes era negado mesmo nos coletivos mistos da época. "O cinema era um assunto de homens, mesmo entre os militantes", como destaca Yvonne Mignot-Lefebvre (1979, p.88).

Um desses coletivos feministas foi o Les Insoumuses, nome que parte de uma brincadeira com as palavras para indicar que suas integrantes eram musas insubmissas. Em 1974, a atriz Delphine Seyrig e a tradutora Iona Wieder participaram de uma oficina de video exclusiva para mulheres com a cineasta Carole Roussopoulos. 0 encontro foi decisivo para a criação de um grupo ativista que, através da realização de filmes coletivos, passou a trocar experiências práticas e artísticas, a investigar situações e repressões vividas por diferentes mulheres e minorias e a propor mudanças tanto no campo do cinema quanto nos costumes da sociedade patriarcal. Como destacam Natasa Petresin-Bachelez e Giovanna Zapperi, "o prazer visual12 é substituído pela invenção de novas formas de agência coletiva e crítica" e, dessa forma, os filmes do coletivo "permitiram a reelaboração da imagem e do olhar em um contexto de luta por autonomia" (2019, p.17).

${ }^{11}$ Como referência para a compreensão do contexto de surgimento desses coletivos, que formam especialmente com o maio de 1968, ver os diversos trabalhos de Guy Gauthier e Sébastien Layerle. 12 A referência aqui é direta a noção de prazer visual trabalhada por Laura Mulvey no texto $O$ prazer visual e o cinema narrativo (1983) que questiona ainda nos anos 1970 um tipo de olhar promovido pelo cinema que coloca a mulher como objeto de observação e prazer por um olhar essencialmente masculino.

Dossiê Crise, Feminismo e Comunicação - https://revistaecopos.eco.ufrj.br/

ISSN 2175-8689 - v. 23, n. 3, 2020

DOI: 10.29146/eco-pos.v23i3.27608 
Carole Roussopoulos foi pioneira e personagem central no ativismo feminista na sua relação com as práticas do vídeo militante. Como destaca Nicole Brenez, Roussopoulos foi a segunda pessoa a comprar uma câmera portátil portaback na França, ainda no ano de 1969 (a primeira foi Jean Luc-Godard). A partir daí, a cineasta "não parou de reinventar formas de ensaio e análise visual documentando lutas feministas, homossexuais, operárias e anti-imperialistas" (Brenez, 2010, p.7). Foram mais de 80 filmes (filmados, dirigidos e montados) ao longo de quarenta anos de carreira. Entusiasmada com os movimentos da época, em 1970 Roussopoulos fundou com o marido Paul o grupo Vidéo Out. A proposta era filmar e dar a palavra às pessoas sem voz, oprimidas e excluídas. Foi assim que registrou os campos palestinos, os integrantes do movimento Black Panther na Argélia e, com a câmera na mão, acompanhou as lutas operárias e feministas nas ruas da França.

Na tese Cinéma et vidéo saisis par le feminisme (France, 1968-1981), Hélene Fleckinger esclarece como a tecnologia do vídeo e o coletivo Les Insoumuses foram inspiradores para a criação de inúmeros coletivos de video feministas na França. Com som sincrônico, mais leve e barato, a câmera de vídeo portátil aparece como uma boa ferramenta para as mulheres se expressarem. Sozinhas ou em coletivos, elas se engajam e "começam a inventar as novas práticas audiovisuais de luta, que rompem com aquelas do cinema militante tradicional" (Fleckinger, 2011, p.324). Ao criar uma prática de vídeo autônoma, as feministas dos anos 1970 reinvestem a noção de realização coletiva: "Se a apropriação de meios e técnicas se coloca como uma necessidade para as mulheres, é porque elas poderiam assim garantir sua autonomia de intervenção e expressão" (Fleckinger, 2011, p.349).

Com o vídeo, as mulheres passam a participar de todas as etapas da produção escapando de uma lógica hierárquica e da divisão do trabalho típicas da prática cinematográfica. Nos coletivos feministas, cada integrante pode se revezar como técnica e artista, além de participar de diferentes etapas da realização. Para Carole Roussopoulos, o mais interessante do vídeo era que se tratava de uma mídia virgem. A ausência de normas autoriza as experimentações e os limites do material são o tempo todo testados: "no clima permissivo, fora das habituais tensões da produção 
cinematográfica, as mulheres (..) podem experimentar com toda liberdade as diversas ofertas desse novo suporte". (Fleckinger, 2011, p.353)

Delphine Seyrig se interessou pelas possibilidades trazidas pela tecnologia do vídeo portátil para explorar experiências de lutas de mulheres, tema que já vinha mobilizando-a ao longo dos anos 1960/70. Atriz de sucesso e musa do cinema de autor francês ${ }^{13}$, Seyrig se torna uma espécie de símbolo de uma feminilidade idealizada. Ao se engajar publicamente em projetos feministas fora da tela, como a luta pelo direito ao aborto, a atriz passa a questionar as ligações entre arte, trabalho, vida pessoal e política.

A atuação em filmes de cineastas mulheres, como Chantal Akerman, Marguerite Duras e Ulrike Ottinger, e as amizades que estabelece no meio, com por exemplo com Agnès Varda, despertam sua percepção crítica sobre o lugar da mulher no cinema como objeto de um olhar masculino. Em Autour de Jeanne Dielman (1975, Sami Frey), vemos Seyrig ao mesmo tempo confusa e seduzida pelo modo diferente como é dirigida por Chantal Akerman no filme Jeanne Dielman, 23 quai du commerce (1975). Em entrevista no documentário, Seyrig explica que aquela era uma visão feminina única, diferente de tudo que já tinha experimentado no set: "filmes geralmente são feitos por homens e, não importa seu ponto de vista ou sensibilidade artística, (...) quando as mulheres falam por si acho que soa totalmente diferente".

Em um dos mais conhecidos trabalhos do coletivo Les Insoumuses, Delphine Seyrig dirige e Roussopoulos filma as entrevistas de Sois belle et tais-toi (1976). Vinte e três atrizes discutem nesse espaço criado para a realização do filme suas experiências no set, o relacionamento com os diretores, a opressão na indústria do cinema, os casos de abuso e exploração. É quando se torna diretora que Seyrig consegue abrir espaço para conhecer a perspectiva de mulheres como Jane Fonda, Maria Schneider, Shirley MacLaine e Viva (atriz e escritora famosa por ter participado de filme de Andy Warhol), entre outras. Junto com as parceiras do coletivo, Seyrig se dedica também a temas que vão além das suas experiências

13 Podemos citar filmes como $O$ ano passado em Marianbad (1961) e Muriel (1963), de Alain Resnais, Beijos roubados (1968), de François Truffaut, A via Láctea (1969), de Luis Bunuel e Pele de asno (1969), de Jacques Demy.

Dossiê Crise, Feminismo e Comunicação - https://revistaecopos.eco.ufri.br/

ISSN $2175-8689$ - v. 23, n. 3, 2020

DOI: $10.29146 /$ eco-pos.v23i3.27608 
profissionais, como o direito das prostitutas e prisioneiras políticas, o engajamento na guerra do Vietnam, a luta pelos direitos humanos.

No trabalho de militância, Delphine Seyrig tinha como interesse primordial organizar uma rede internacional de mulheres para mostrar suas lutas ao redor do mundo, sempre usando o vídeo como forma de explorar uma espécie de agenda política. A própria difusão do material produzido pelo coletivo era pensada estrategicamente como um momento chave, com o intuito de promover o debate sobre o que tratava. Os filmes circulavam em festivais de cinema internacionais, em semanas de debates organizados por grupos de mulheres e em salas de cinema em Paris.

Consciente da importância da formação dessa rede, Seyrig aposta na realização de seu primeiro vídeo, um cine-tract, um tipo de filme curto, produzido na urgência do momento, que tem como função tornar conhecida uma luta. Inês é produzido para fazer parte de uma ação internacional: uma campanha que exigia a libertação imediata da presa política brasileira Inês Etienne. 0 filme é também fruto dos encontros e afetos produzidos no interior das redes feministas, entre eles o encontro entre Delphine Seyrig e a cineasta e atriz brasileira Norma Bengell.

Inês

Em autobiografia publicada em 2014, a atriz Norma Bengell relata em detalhes como conheceu Delphine Seyrig e sua participação na produção de Inês. Segundo Bengell, o encontro entre as atrizes francesa e brasileira foi promovido por Simone de Beauvoir após um pedido de ajuda vindo de Bengell para o caso de Inês Etienne. No livro, Bengell narra que teria vindo de Seyrig a ideia de fazer um vídeo "que poderia ser rodado na casa de Régis Debray, um pequeno estúdio improvisado, em videocassete, uma técnica nova que era muito livre e rica” (Bengell, 2014, p.186).

0 testemunho de Bengell é corroborado pela historiadora Isabel Cristina Leite (2019), que a partir de uma minuciosa pesquisa nos arquivos pessoais de Inês Etienne recompôs a rede de encontros que levariam Bengell a Inês Etienne, e Inês Etienne a Delphine Seyrig. A historiadora relata que a figura central dessa articulação teria sido a jornalista Márcia Almeida, que conheceu a irmã de Inês no 
início dos anos 1970, em Paris, na casa de Norma Bengell. Lá foi apresentada à história da militante e decidiu começar um movimento para que Inês não fosse esquecida na prisão, o filme seria, portanto, uma das estratégias desse movimento articulado em rede ${ }^{14}$.

0 curta de vinte minutos abre com uma fotografia de Inês Etienne produzida no contexto do seu julgamento. Um ruído incômodo, um tremor ininterrupto e as ranhuras na imagem preto e branca afastam o espectador ao mesmo tempo em que o olhar de Inês o atrai, um olhar enigmático que escapa da câmera naquele momento de tensão. Sobre a imagem, uma voz em off feminina (identificada por Norma Bengell em sua biografia como sendo de Delphine Seyrig) narra a vida cotidiana da jovem Inês antes do golpe de 1964 e a brusca interrupção da sua rotina pelos atos cometidos pelo Estado brasileiro. Ainda sobre a foto, a narradora relata em detalhes os movimentos sinistros que levaram Inês à Casa da Morte como prisioneira política e o cotidiano no centro de tortura:

(Inês) passará 100 dias, 100 dias de interrogatório, de morte simulada, de tortura cotidiana. Ela não vê nenhum outro prisioneiro, ela escuta somente seus gritos, seus choros e suas músicas, os policiais colocavam discos durante as sessões de tortura, cada prisioneiro tinha direito a sua canção, aquela utilizada durante 100 dias para Inês, se chamava Amada Amante ${ }^{15}$ (Inês, 1974, video).

Corte seco da fotografia de Inês Etienne para o plano de uma mulher acuada no canto da parede com um saco preto cobrindo o rosto. 0 corte é seguido pela música Amada Amante na voz de Roberto Carlos, que como já adiantou o off, era a trilha tema das sessões de tortura vivenciadas por Inês. A partir desse momento, o filme assume a performance como seu dispositivo central, a atriz retira o saco preto

\footnotetext{
${ }^{14}$ Alguns anos mais tarde, em um carta de Márcia para a presa política, a jornalista continuava reiterando a importância de soltar notas em jornais, coletar depoimentos e dar publicidade a história de Inês, como uma forma de pressionar o governo pela liberdade da presa política: "eu quero te ver aqui fora e sei que é isso que você mais quer. Mas para isso a gente tem que berrar, gritar, contar que você tá aí dentro, que tudo isso é uma putaria mesmo e manter repetindo isso cada vez mais" (Almeida, 1979).

15 Tradução nossa.
}

Dossiê Crise, Feminismo e Comunicação - https://revistaecopos.eco.ufrj.br/

ISSN $2175-8689$ - v. 23, n. 3, 2020

DOI: 10.29146/eco-pos.v23i3.27608 
do rosto e se despe sozinha diante da câmera. A banda sonora é composta pelo rock melódico de Roberto Carlos e uma voz masculina que interpreta o torturador repetindo comandos humilhantes e explorando a condição feminina da presa política: "para assaltar banco não tinha vergonha (...) não arruma a calcinha não, vai ter que tirar ela também (...) vira sua cadela (...) vamos que eu quero ver esse corpinho que muito comunista já viu e já comeu" (...) você vai ser obrigada a ter um filho da gente", e assim por diante.

São sete longos minutos, neles a imagem se torna cada vez mais violenta. Do torturador apenas ouvimos a voz e vemos de vez em quando as mãos que entram em quadro para espancar ou manipular o aparelho de choque. Quem ocupa o centro da imagem é sempre o corpo nu da atriz que se retorce diante da câmera submetido ao espancamento e aos choques elétricos. A performance assume um caráter realista, quebrado apenas pela maquiagem do rosto da atriz, olhos negros e máscara branca carregada, talvez com a intenção de evidenciar a performance, ou ainda de preservar sua identidade (o filme não possui créditos finais).

O dispositivo da performance no video, como destaca Phillipe Dubois, foi usado em suas origens como estratégia para fazer emergir o real em toda a sua brutalidade. Esse caráter realista questionava as narrativas dramáticas como conhecidas até então no cinema. 0 exemplo trazido por Dubois para ilustrar essa prerrogativa é o dos vídeos de Vito Acconci, um dos fundadores da videoperformance no início dos anos 1970. Chamamos a atenção para Pryngs, de 1971. Neste video, os corpos de Acconci e de Kathy Dillon são encerrados na imagem em um enquadramento fechado e sufocante. 0 homem violenta a mulher ao tentar abrir os olhos que ela insiste em manter fechados. A fixidez e unidade do plano tornam a cena de violência ainda mais intensa.

São 17 minutos de um "espetáculo aterrorizante" que, para Dubois, fica ainda mais terrível por conta da "consciência visual dos gestos no plano", do enquadramento, da luz, dos grãos, dos cinzas, dos desfocamentos dos movimentos, da "duração intensiva da cena que instaura um tempo de tensão" (2004, p. 104). Dubois sugere ainda que a vertente do vídeo baseada nas performances, "na exposição bruta dos corpos ou na duração contínua das ações, é atravessada por

Dossiê Crise, Feminismo e Comunicação - https://revistaecopos.eco.ufri.br/

ISSN 2175-8689 - v. 23, n. 3, 2020

DOI: 10.29146/eco-pos.v23i3.27608 
essa dimensão de consubstancialidade bruta entre imagem e dispositivo (2004, p.105).

Em Inês, o corpo feminino enclausurado pelo enquadramento da câmera está também fechado em um cômodo inóspito e encurralado pela câmera contra as paredes. A violência física e psíquica da performance é acentuada pelas palavras de ordem violentas que reproduzem a interpretação do torturador, das mãos e do falo que surgem do fora de campo para violentar e perturbar esse corpo fragilizado. Se as ranhuras da imagem, o desfocar constante e o som intermitente e sufocante provocam um profundo incômodo, o silêncio e a paralisia que vem depois são ainda mais perturbadores. A atenção se volta exclusivamente para a longa imagem do corpo estendido, machucado, coberto de sangue artificial.
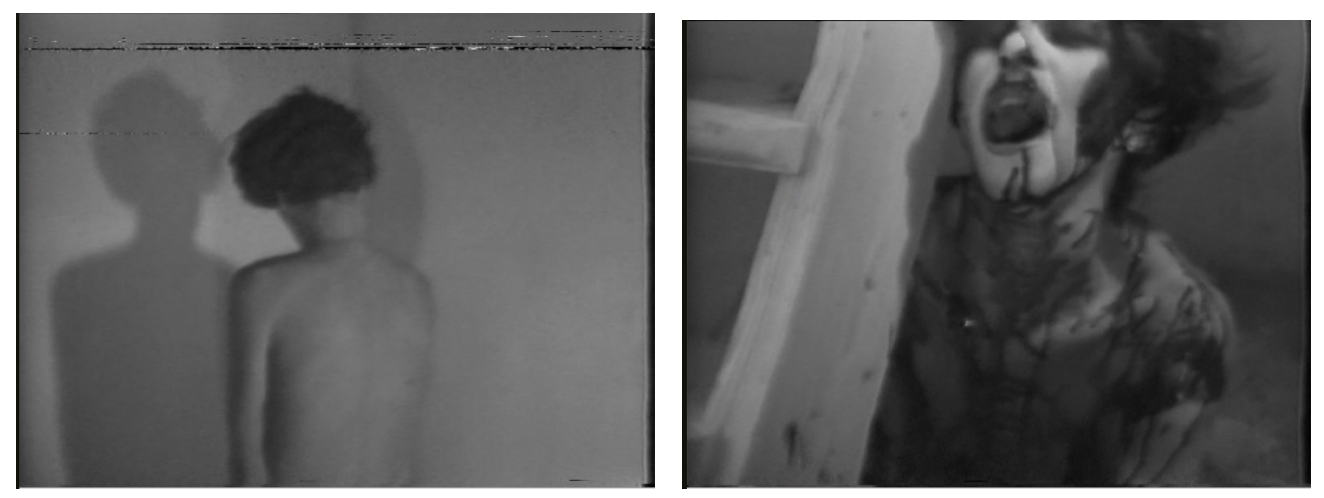

FIG. 2 - Fotogramas Inês, 1974, Delphine Seyrig

Ao contrário do video de Acconci, feito por um homem interessado nas possibilidades estéticas e sensoriais do novo dispositivo, Inês é todo pensado, organizado e estruturado por mulheres que se reúnem coletivamente e usam esse dispositivo do video com um intuito determinado. 0 que está em jogo em Inês, não é apenas a produção de uma "imagem efetiva e forte" (Dubois, 104) para testar a interação com o espectador, mas sim o uso dessa intensidade para mobiliza-lo, para desvelar as minúcias de falas, gestos e ações bárbaras cometidas por vozes e corpos masculinos contra mulheres vulneráveis. A tortura se torna imagem não apenas no ato de violência e nos estremecimentos do corpo, mas também nos detalhes do movimento desse corpo durante a performance. São pequenos gestos que desvelam 
a intimidação cotidiana desse olhar masculino sobre corpos femininos: diante da câmera (que reproduz esse olhar) os braços cobrem as partes íntimas, a cabeça se abaixa, as costas se encurvam na tentativa possível de evitar mostrar o que é sadicamente desejado pelo opressor. Em meio a performance, um breve flash com a fotografia de Inês atua como um soco: a mulher torturada está ali, ela existe e precisa de ajuda.

A cena seguinte seguirá com o dispositivo da performance, mas em outro ambiente e com o retorno da voz feminina em off. Em um jardim a câmera observa de longe o corpo da atriz que reaparece rastejando, agora vestida, mas carregando as marcas da tortura. A narração descreve o retorno de Inês para casa, a história parece tirada de um filme de terror, mas o relato é verídico:

(...) no mês de agosto de 1971 um policial de Minas Gerais avisa à família de Inês que ela está morta há 40 dias. A família se apresenta diante das autoridades militares para lhes comunicar a morte de Inês, essa falsa informação, na realidade, salvou a vida de Inês. Quando a família reclama o corpo de Inês e a polícia não tem um cadáver de 40 dias para apresentar, os policias não veem outra saída a não retirar Inês do centro de tortura e depositá-la na no jardim da casa dos seus pais. Com um grande esforço ela chega até a porta e sua família revê Inês pela primeira vez, depois de 100 dias. Ela era um verdadeiro esqueleto, ela estava em pânico, certa de que os policiais metralhariam a casa, matariam os adultos e as crianças, ela pedia um revólver para se matar antes que a polícia o fizesse (...) depois de 100 dias de tortura, de terror, ela só falava da morte, ela não queria ameaçar a vida de sua família. No final da rua os policiais esperavam que alguém da família saísse com Inês, assim eles poderiam matá-la e se justificar depois: "a terrorista que vocês procuravam, nós a abatemos em fuga perto de uma casa em Belo Horizonte". Mas conscientes dessa ameaça a família de Inês torna a situação pública, imediatamente ascendem as luzes da casa, telefonam aos amigos e ao hospital demandando uma ambulância e um serviço médico. Dizem simplesmente, que se trata de um caso muito grave e urgente. A ambulância chega e conduz Inês a uma clínica. O carro policial a segue, mas não pode fazer nenhum atentado (Inês, 1974, video).

A sequência filmada no jardim tem 4 minutos de duração. Além da narração transcrita acima, o off recupera a trajetória de Inês: da internação no hospital à condenação perpétua e à prisão em Bangu. No momento em que o vídeo é realizado 
Inês cumpre seu terceiro ano de prisão e advoga pelo direito legítimo de revisão da pena. Os últimos dois minutos de filme retornam à fotografia que abriu a obra, Inês em seu julgamento, e sobre ela a leitura de uma carta manifesto.

Segue a resolução votada por unanimidade pelo Congresso Internacional de Mulheres em Frankfurt em 16 e 17 de novembro 1974: Nós, do congresso internacional do movimento de liberação das mulheres em Frankfurt, somos informadas que Inês Etienne Romeu foi torturada pela polícia brasileira, todos os dias pelo período de 100 dias, e violada por um dos seus torturadores, do qual ela ficou grávida. Ela foi condenada à prisão perpétua. Não podemos ignorar que legalmente Inês possui hoje o direito de revisão do seu processo, e que esse direito lhe foi recusado. 0 congresso resolveu, pela ocasião do ano de 1975, ano proclamado pela ONU como ano internacional das mulheres, denunciar e julgar diante de um tribunal internacional de mulheres, todos os responsáveis de crimes contra as mulheres. Nós desafiamos o General Geisel, novo Presidente da República no Brasil, que afirmou ser o verdadeiro defensor das liberdades democráticas de colocar em liberdade imediata Inês Etienne Romeu e de garantir que seu torturador? ser julgado o mais breve possível (Inês, 1974, video).

A partir dessa tática de divulgação de uma história ainda silenciada, o vídeo que surge do encontro de Bengell e Seyrig é exibido não só no Congresso Internacional de Mulheres em Frankfurt, em 1974, mas também em outros festivais, como o de cinema de Knokke-le-Zoute, na Bélgica. Sobre a potente carta que fecha o filme permanece uma lacuna. Em sua autobiografia, Bengell afirma ter sido ela quem escreveu a carta de encerramento, e que esta seria endereçada diretamente ao Presidente Ernesto Geisel "pedindo a revisão do processo (de Inês) em nome da democracia" (Bengell, 2014, p.186). No entanto, a partir das pesquisas que realizou em arquivos do coletivo feminista, a historiadora Hélène Fleckinger revela que a carta teria sido escrita coletivamente e publicada na revista Nouvelles Feministes, Journal de la Ligue de Femme de janeiro de 1975.

As narrativas divergentes nos contam um pouco do próprio processo de produção da obra. Realizado na urgência do acontecimento, pensado como agente e motor da história, o filme militante pertence ao seu tempo presente. Inês não possui cartela com título ou créditos de realização, para reconstruir seu processo de 
fabricação é preciso percorrer uma rede de emaranhados feitos de afetos, desejos e parcos documentos.

0 resultado concreto desse encontro das feministas com o filme foi uma grande campanha internacional que, ao longo de 1975, foi responsável pelo envio de dez mil cartões postais às embaixadas no Brasil em vários países pedindo a libertação de Inês Etienne. Como afirma Hélene Fleckinger, "O impacto do vídeo nessa mobilização internacional é indispensável: ele foi pensado para jogar essa função de panfleto (tendo em conta a força específica da linguagem audiovisual), e esse fato condicionou sua circulação, de grande escala" (2011, p.390).

Por outro lado, a recepção do filme também gerou tensões e polêmica entre as espectadoras. Em entrevista a Hélene Fleckinger, Iona Wieder conta que, depois da exibição de Inês em um festival de Bruxelas, as integrantes do coletivo foram questionadas sobre o fato de evocar a tortura justamente a partir da encenação de um corpo feminino. Segundo Wieder, quando questionada Delphine respondeu: "Não falamos jamais de mulheres quando denunciamos a tortura, falamos sempre dos homens! Tomamos conhecimento que sempre que há uma guerra são as mulheres que são feitas de reféns e estupradas" (Wieder apud Fleckinger, 2011, p.553).

Norma Bengell, em suas memórias, também faz referência à cena da tortura:

Idealizei, peguei e fiz os cenários do filme: cadeira de choque elétrico, pau de arara etc. Fiz uma história humana, nada panfletária, sem citar o nome de Inês, denunciando o estupro. A violência não tem nome, e as mulheres, quando são torturadas, levam desvantagem pelo estupro, que traz doenças e gravidez. Era a primeira cena de estupro mostrada em um filme, revelando um falo que não dá prazer, que era como uma arma $(2014,186)$.

É difícil afirmar com certeza de quem foi a concepção do filme realizado à várias mãos, mas fica claro que tanto para Bengell como para Seyrig mostrar o corpo nu da atriz através de um olhar objetificante fazia parte de uma estratégia política. Bengell, já tinha experimentado uma situação parecida em Os Cafajestes (1962), de Ruy Guerra. A cena protagonizada por Bengell se tornou um ícone da história do 
cinema brasileiro por trazer o primeiro nu frontal para as telas, não para erotizar, mas para criticar a violência do olhar masculino sobre o corpo feminino.

O cruzamento da análise das imagens com o testemunho de Bengell e os documentos que restaram sobre a produção do filme explicitam um tipo de violência que se materializa em diferentes intensidades e camadas, mas que afeta as mulheres de um modo singular. De forma autônoma, essas mulheres denunciam o olhar masculino opressor, a coisificação de seus corpos e a barbárie da misoginia da tortura. Se falo e arma são os objetos repressores, quando são as mulheres que seguram a câmera é possível reforçar como ele são usados para produzir violência. Denunciar a misogenia através das imagens e sons performáticas, e fazê-las circular, é como dar um grito que reverbera dessa rede de afeto e apoio coletivos.

\section{Considerações finais}

Em 29 de agosto de 1979, com a aprovação da Lei da Anistia, Inês Etienne Romeu é libertada. Ela havia cumprido oito anos de pena. Uma semana depois, registrou uma longa denúncia na $\mathrm{OAB}$ do Rio de Janeiro. Listou nove nomes de desaparecidos políticos que passaram pela Casa da Morte e de seus algozes. Em 1979, quando saiu da prisão, Inês foi filmada por Norma Bengell. 0 filme está guardado junto aos arquivos da atriz na Cinemateca Brasileira, onde passava por um processo de restauração. Não sabemos qual a situação do material no momento e tivemos que interromper essa etapa da pesquisa por conta da paralização dos trabalhos da instituição e da indefinição do seu futuro a partir dos atos cometidos pelo Estado brasileiro. A imersão na trajetória, lutas políticas e feministas e relação de Norma Bengell com outras militantes será a próxima etapa dessa pesquisa.

Dela também fará parte outros vídeos e documentos, como a reportagem de tevê realizada no início de 1981 com Inês, quase dez anos após a sua prisão, em que ela reconhece o local da Casa da Morte e o dono do imóvel, Mário Lodders. 0 encontro entre os dois, acompanhado por jornalistas, membros do Congresso Nacional e $\mathrm{OAB}$, foi todo filmado. Os dois minutos de imagem restantes, com som 
ambiente, mostram uma mulher destemida que confronta o dono da casa, diz que o reconhece e faz o homem admitir que a conhecia' ${ }^{16}$.

Inês morreu em 2015. Nas décadas seguintes à libertação, denunciou nomes e reconheceu fotografias de torturados, torturadores e a verdadeira identidade do psicanalista Amílcar Lobo, médico que atendia os presos no cativeiro e dizia aos carrascos até quando as vítimas aguentavam mais torturas. Também encarou e reconheceu Antonio Fernando Hugues de Carvalho, o torturador que havia denunciado em 1971.

Como aponta ainda o relatório, a Casa da Morte estava entre "os imóveis disponibilizados por particulares e foram montados para não deixar vestígios dos crimes neles cometidos". Os depoimentos dos agentes da repressão confirmam que deixar Inês Etienne sair viva de lá foi considerado um erro. 0 Coronel Paulo Malhães, responsável pelo centro clandestino de tortura e morte, confirmou que foi Inês Etienne que "derrubou a Casa de Petrópolis ... derrubou quando reconheceu a casa".

O conhecimento desse trágico e violento passado tornam as imagens do casamento de Inês e Jarbas e o filme de Delphine Seyrig ainda mais preciosos. Eles são como um lampejo, uma luz que faz visível e guarda para a posteridade os gestos, a expressão, o olhar de quem foi testemunha e vítima das barbaridades cometidas pelos Estado no período da ditadura militar brasileira, assim como a mobilização dessa rede de mulheres na luta pela liberdade de Inês. Guardados por décadas em um fundo de gaveta ou em um acervo internacional, esses filmes são preciosas fontes testemunhais que apontam a importância da busca de vestígios do passado, de imagens perdidas, para a compreensão da exploração da condição das mulheres durante a prisão e tortura, assim como da luta de mulheres para denunciá-la quando seguram em câmeras.

\section{Referências bibliográficas:}

BENGELL, Norma. Norma Bengell. São Paulo: Versos Editora, 2014

\footnotetext{
16 Essa imagem faz parte do acervo da Rede Globo e foi anexada aos relatórios da Comissão Nacional da Verdade.
}

Dossiê Crise, Feminismo e Comunicação - https://revistaecopos.eco.ufri.br/

ISSN $2175-8689$ - v. 23, n. 3, 2020

DOI: 10.29146/eco-pos.v23i3.27608 
BRASIL. Comissão Nacional da Verdade. Relatório da Comissão Nacional da Verdade. Brasília: CNV, 2014

BRENEZ, Nicole. Carole Roussopoulos ou l'attention créatrice. In: Caméra Militante - Luttes de libération des années 1970. Paris, MetisPresses, 2010

DUBOIS, Phillipe. Cinema, video, Godard. Cosac e Naif, 2014.

FLECKINGER, Hélène. Cinéma et vidéo saisis par le feminisme (France 1968-1981). Thèse de doctorat en études cinématographiques et audiovisuelles. UNIVERSITÉ SORBONNE NOUVELLE - PARIS 3, 2011

. Une camèra à soi. Quand les féministes s'emparent de la video. In: Caméra Militante - Luttes de libération des années 1970. Paris, MetisPresses, 2010

GOLDBERG, A. Feminismo e autoritarismo: a metamorfose de uma utopia de liberação em ideologia liberalizante. Dissertação de Mestrado em Ciências Sociais, IFCS, UFRJ, Rio de Janeiro: 1987.

LEITE, Isabel Cristina.Fragmentos da vida de Inês Etienne Romeu: o encarceramento no presídio Talavera Bruce (1972-1979). Revista do Arquivo Geral da Cidade do Rio de Janeiro, n.16, 2019.

LINDEPERG, Sylvie. Nuit et Brouillard- un film dan l'histoire. Odile Jacob, Janvier 2007. . Des lieux de mémoire portatifs. Entretien réalisé par Dork Zabunyan. Critique: Revue générale des publications françaises et étrangères. Paris: Les Éditions de Minuit, Mars 2015.

MAROTTA, Letícia. Formas cinematográficas de rememoração da ditadura militar pelas mulheres; uma análise do filme Retratos de identificação. Dissertação de mestrado. Universidade Federal de Minas Gerais, 2019.

MIGNOT-LEFEBVRE, Yvonne. L'appropriation de la vidéo par les femmes, CinémAction, n.9, automne 1979.

MULVEY, Laura. Prazer visual e cinema narrativo. In: XAVIER, I. A experiência do cinema. Rio de Janeiro: Edições Graal, 1983.

PETRESIN-BACHELEZ, Natasa e ZAPPERI, Giovanna. Defiant Muses: An introduction. Catálogo da exposição no Museu Reina Sofia, Madrid, 2019.

https://issuu.com/museoreinasofia/docs/musas ingle s-cata logo/ Acesso em julho 2010.

TEGA, Danielle. Mulheres em foco: construções cinematográficas brasileiras da participação política feminina / Danielle Tega. São Paulo, Cultura Acadêmica, 2010.

TELES, Maria Amélia de Almeida. Violações dos direitos humanos das mulheres na ditadura. Estudos Feministas, Florianópolis, 23(3): 406, setembro-dezembro/2015 